\title{
Klaus Dresing, Peter Trafton, Jos Engelen (Cast technician): Casts, splints, and support bandages: nonoperative treatment and perioperative protection
}

\section{Thieme Verlag, New York, Stuttgart, Delhi, Rio, 2015, 652 pp, 2497 illustr., Hardcover, EUR (D) 159,99 EUR (A) 164.50 CHF 224,00, ISBN: 978-3-13-175341-0}

\section{Pierre Kehr ${ }^{1}$}

Received: 24 July 2015/ Accepted: 25 July 2015/Published online: 21 August 2015

(C) Springer-Verlag France 2015

This monumental work constitutes a true encyclopedia of the preserving orthopedic treatments, casts, splints, and bindings that are explained and presented in detail.

After a background historical and exposed principles, one enters the important chapter of the nonpharmacological and pharmacological prevention of thromboembolic complications. The means and materials with their specific properties are then studied. The specific techniques for the fractures, dislocations, and subluxations of the upper limb, then of the lower extremity, the fractures of the spine, the fractures in paediatrics then arrive. The traumas of the tendons, ligament, and nerves are the object of specific chapters. Finally, the infections and the lesions by overload are not omitted.

Especially, more than 300 pages of color photographs which show all the stages of manufacturing of each orthesis or cast the follow.
More: the very beautiful quality of the iconography and the access to the site "Mediacenter.thieme.com" on which one will be able then, thanks to the code provided in the work (page 2 of cover), to show the videos of all the techniques.

Small "less": one can regret the absence of an index to facilitate the rapid access with the various entries.

Very beautiful work which should be accessible in all services from orthopedy to the future doctors and to gypsotherapistes.

Compliance with ethical standards

Conflict of interest None.

Pierre Kehr

pierre.kehr@gmail.com

1 Strasbourg, France 